EC

30,6

802

Received 3 June 2012

Revised 6 December 2012

Accepted 4 January 2013

\section{Punching shear analysis of slab-column connections}

\author{
Carlos L. Moreno
}

Laboratory for the Concrete Technology and Structural Behaviour (LABEST) and Applied Mechanics Department, School of Technology and Management, Polytechnic Institute of Bragança, Bragança, Portugal, and

\author{
Ana M. Sarmento
}

Laboratory for the Concrete Technology and Structural Behaviour (LABEST) and Civil Engineering Department, Faculty of Engineering, University of Porto, Porto, Portugal

\begin{abstract}
Purpose - The paper aims to present an experimental testing program regarding reinforced concrete slabs, with and without shear reinforcement, submitted to punching under both symmetric and eccentric loading. Comparisons between numerical simulations and experimental behaviour results are carried on. The capabilities and limitations of the numerical model to reproduce the brittle punching-shear failure are discussed.

Design/methodology/approach - The paper opted for a performance assessment of a numerical model, comparing FEM results with known experimental tests properly instrumented. Capability of DIANA software to simulate the punching behaviour of slabs is discussed.

Findings - The paper demonstrates that the mechanical properties assigned to the element layer containing the bending reinforcement impose the load deflection stiffness behaviour. Good agreement was found between the predicted and the observed deformation behaviour. Nevertheless, the reproduction of the punching ultimate capacity is strongly dependent on the adopted value for the shear retention factor, which appears to be the major decisive parameter.

Originality/value - This paper demonstrates that the smeared crack model based on both the concept of strain decomposition (SD) and total strain with fixed orthogonal cracks approach (TSF) can correctly be used for the analysis of the behaviour of slabs submitted to punching shear.

Keywords Punching shear, Load eccentricity, Shear reinforcement, Fracture mechanics, Shear strength, Shearing, Reinforced concrete

Paper type Research paper

\section{Introduction}

Punching in slabs is usually associated to the application of concentrated loads or to the presence of columns. One of the main concerns related to flat slabs is its punching shear capacity at slab-column connection, which is subjected to a very complex three-dimensional stress state. Punching-shear failure is hence characterized by the development of a truncated cone shaped surface at the slab-column connection. This type of failure is usually both brittle and catastrophic once it may generate the global collapse of the structure due to the increasing load transfer to neighbouring columns.

In the experimental program carried out by the authors, high strength concrete (HSC) slabs $(2.5 \times 2.5 \times 0.18 \mathrm{~m})$, with and without shear reinforcement, are loaded through a central column and subjected to concentric and eccentric loading (Moreno and Sarmento,

2008; Moreno, 2010). Normal and steel fibre (SFRC) self-compacting concretes are used for
\end{abstract}

Engineering Computations: International Journal for Computer-Aided Engineering and Software

Vol. 30 No. 6, 2013

pp. $802-814$

(C) Emerald Group Publishing Limite 0264-4401

DOI 10.1108/EC-Jun-2012-0122 
the slab models. The effects of double-headed studs and of the steel fibres as shear reinforcement are also observed.

Numerical simulation of brittle shear behaviour as punching failure is very complex. Therefore, a great research effort is being made on the improvement of numerical models in order to fully reproduce the behaviour of reinforced concrete flat slabs failing in punching. The accuracy and the reliability of these numerical models can be achieved by comparing them with data from experimental tests on properly instrumented real scale specimens.

In the present paper the behaviour of concrete slabs failing in punching is simulated by using a non-linear three-dimensional finite element analysis (FEA) model based on the concept of the smeared crack model approach, both with and without strain decomposition. Cracking is thus specified as a combination of tension cut-off, tension softening and shear retention. The slabs are fully simulated in order to account for the eccentrically applied loading without taking care of two-way symmetrical conditions.

The experimental behaviour of the slab-columns connections is successfully reproduced. The numerical ultimate punching shear capacity shows, as well, good agreement with test data. The numerical brittle punching shear collapse is plainly identified by mean of comparison between the critical stress state and the corresponding failure surface.

\section{Eexperimental programme}

\subsection{Specimens geometry}

Six reinforced concrete flat slab models, $2,500 \mathrm{~mm}$ square and $180 \mathrm{~mm}$ height, supported on eight points equally spaced along a $2,165 \mathrm{~mm}$ diameter perimeter, were loaded through a central square concrete column $250 \times 250 \mathrm{~mm}^{2}$ (Figure 1).

\subsection{Test setup}

A central load was applied on slabs AC0, FC0 and ACA1, whilst the load has been transmitted with a $200 \mathrm{~mm}$ eccentricity ( 0.8 of the column side dimension) on AE0,

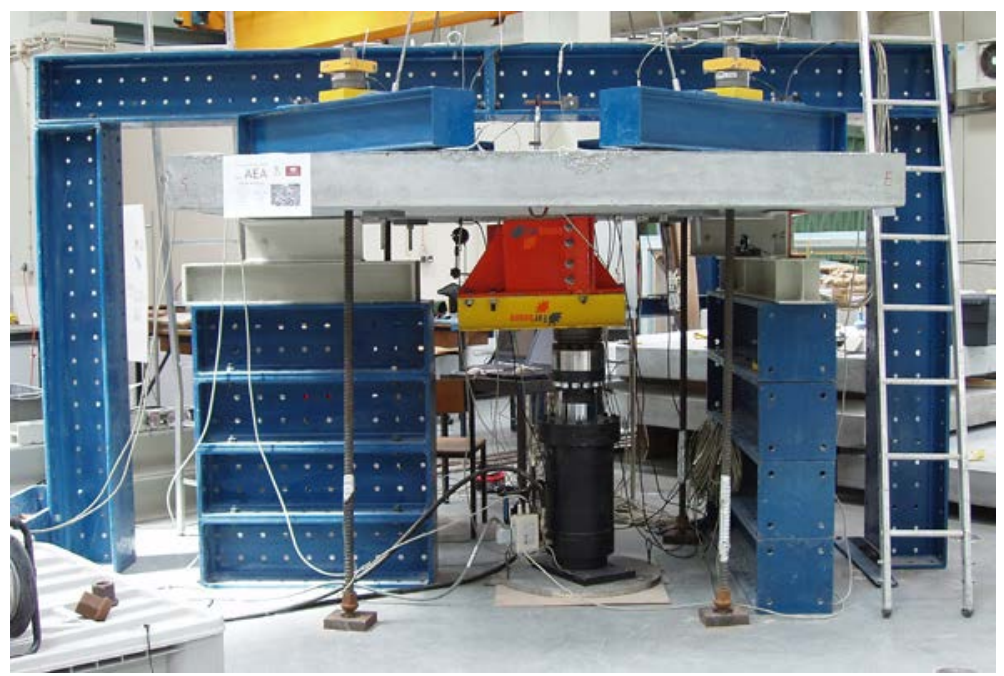

Note: Eccentrically loaded test specimen in photo

\section{Punching shear analysis}

803
Figure 1.

General overview of tests setup 
EC

30,6

804

FE0 and AEA1 slabs. Eccentrically loaded tests were carried out using a steel adapter confining the column stub and by moving the actuator by a distance equal to the specified value of the load eccentricity.

Tests were performed with a servo-hydraulic test system by means of controlling the vertical displacement of the column under a constant displacement rate of $0.18 \mathrm{~mm} / \mathrm{min}$, so that the response after peak load is captured. A deformation-controlled hydraulic jack with a nominal range of $1,000 \mathrm{kN}$ was utilized. Tests were carried out at the Laboratory for the Concrete Technology and Structural Behaviour (LABEST) of the University of Porto.

\subsection{Materials}

Table I shows the concrete mix proportions for both HSC and SFRC. The main difference between both concretes is the used water proportion in order to maintain acceptable workability.

The bending reinforcement of slabs was: on the top (tensile) orthogonal reinforcement, $16 \mathrm{~mm}$ diameter $\left(\mathrm{f}_{\mathrm{y}}=550 \mathrm{MPa} ; \mathrm{f}_{\mathrm{u}}=650 \mathrm{MPa}\right.$; $\mathrm{E}_{\mathrm{s}}=200 \mathrm{GPa}(\mathrm{LNEC}$, 1998, 2002)), spaced $125 \mathrm{~mm}$. The bars were folded up at both ends to promote better anchorage. The ratio $\rho$ of top flexural reinforcement was 1.17 per cent. On the bottom (compressive) the flexural reinforcement was $8 \mathrm{~mm}$ diameter bars $\left(\mathrm{f}_{\mathrm{y}}=550 \mathrm{MPa}\right)$ each direction spaced $250 \mathrm{~mm}$. Concrete cover $(\mathrm{c}=20 \mathrm{~mm})$ was assured by using concrete spacers. Details of flexural reinforcement are shown in Figure 2.

Cement CEM II\A 42.5R (c)

Fly ashes

Sand 1 (fine)

Sand 2 (coarse)

Table I.

Concrete mix composition $\left(\mathrm{kg} / \mathrm{m}^{3}\right)$
Gravel

Super-plasticiser $\left(\mathrm{S}_{\mathrm{p}}\right)$

Water (w)
390

110

351

437

897

7.5

157 (HSC) - 164 (SFRC)
Figure 2.

Details of flexural and shear reinforcement

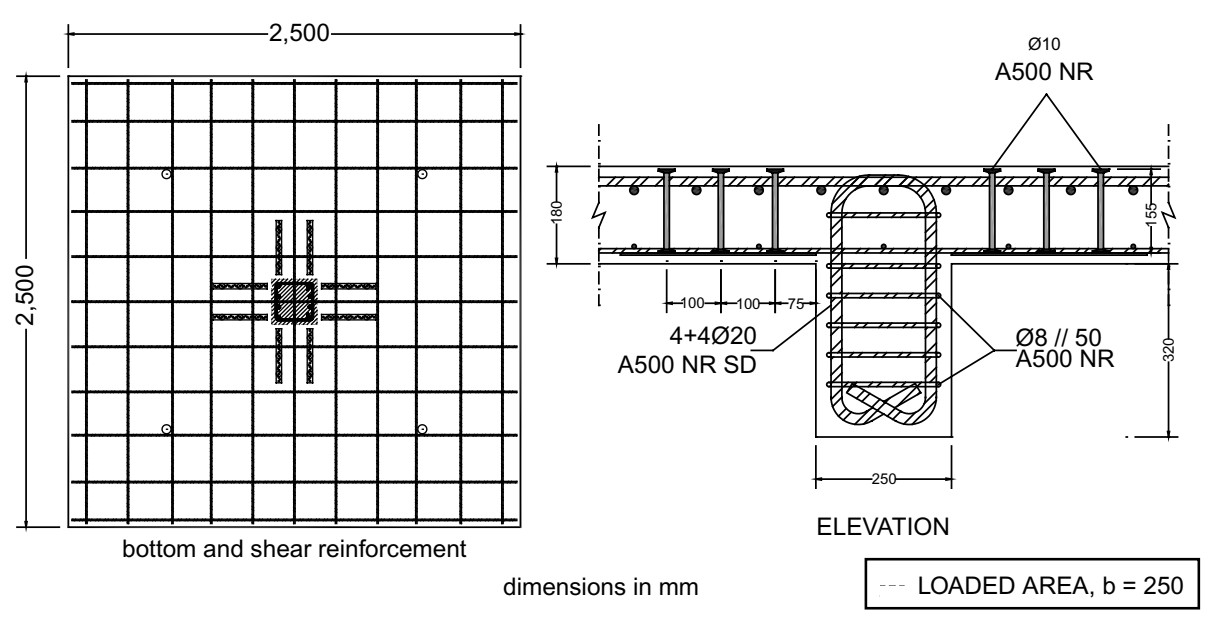


Shear reinforcement (with mechanical characteristics as defined in LNEC (1998) and ITeC (2006)) was used in two of the slabs, ACA1 and AEA1, comprising 24 headed studs well anchored at their extremities and made with $10 \mathrm{~mm}$ diameter rebar $\left(f_{\mathrm{yw}}=500 \mathrm{MPa}\right)$, placed in three perimeters perpendicularly to the column face, as shown in Figure 2. The first perimeter of shear elements was placed at a distance of approximately half effective depth $(\mathrm{d} / 2)$ from the column face.

FC0 and FE0 slabs were casted with SFRC. The steel fibres are Dramix RC-65/60-BN with hooked ends (characteristics as defined by supplier: $f_{y f}=1,000 \mathrm{MPa}$, $\varnothing_{\mathrm{f}}=0.90 \mathrm{~mm}, 1_{\mathrm{f}}=60 \mathrm{~mm}$ ). The volume of fibres is 0.5 per cent of concrete volume (approximately $39.25 \mathrm{~kg}$ per concrete cubic meter). Concrete characterization results determined according to Portuguese and European Standards (IPQ, 2003a, b, c; LNEC, 1993) are presented in Table II.

\subsection{Instrumentation}

Loading was measured directly by a load cell incorporated in the test system, and indirectly by the strains in the supporting rods by two resistance strain gauges glued to opposite sides of the bars (average value). Measurements of concrete deformations and shear reinforcement strains were also carried out. Concrete strains in radial and tangential directions were measured on the bottom (compression) side and on the top side (crack opening) of the slabs with electrical resistance gauges (Omega), fixed to the concrete surface at various distances from the column, Figure 3. Five $100 \mathrm{~mm}$ length gauges were used for compression strain measurement; for tension (crack opening) strains gauge lengths are shown in Figure 3 (left hand side). Strains in six of the shear studs were measured by $8 \mathrm{~mm}$ length strain gages. Test data was automatically stored into a personal computer through a data acquisition system.

\begin{tabular}{|c|c|c|c|c|c|c|}
\hline Slab & $\begin{array}{l}\text { Age } \\
\text { (days) }\end{array}$ & $\begin{array}{c}\text { Average specific } \\
\text { weight } \\
\rho_{\mathrm{cm}}\left(\mathrm{kg} / \mathrm{m}^{3}\right)\end{array}$ & $\begin{array}{c}\text { Modulus of } \\
\text { elasticity } \\
\mathrm{E}_{\mathrm{cm}}\left(\mathrm{N} / \mathrm{mm}^{2}\right)\end{array}$ & $\begin{array}{c}\text { Compressive } \\
\text { strength } \\
\mathrm{f}_{\mathrm{cm}, \mathrm{cil}}\left(\mathrm{N} / \mathrm{mm}^{2}\right)\end{array}$ & $\begin{array}{c}\text { Tensile } \\
\text { strength } \\
\mathrm{f}_{\mathrm{ct}}\left(\mathrm{N} / \mathrm{mm}^{2}\right)\end{array}$ & \\
\hline $\mathrm{ACO}$ & 71 & 2,255 & 31,550 & 56.1 & 3.78 & \\
\hline ACA1 & 64 & & & 54.4 & 3.94 & \\
\hline AE0 & 149 & & & 65.6 & 3.74 & \\
\hline AEA1 & 142 & & & 66.2 & 4.53 & Table II. \\
\hline $\mathrm{FC} 0$ & 79 & 2,291 & 29,500 & 39.3 & 3.49 & Concrete mechanical \\
\hline FE0 & 73 & & & 36.9 & 3.50 & properties \\
\hline
\end{tabular}

\section{Punching shear analysis}

805

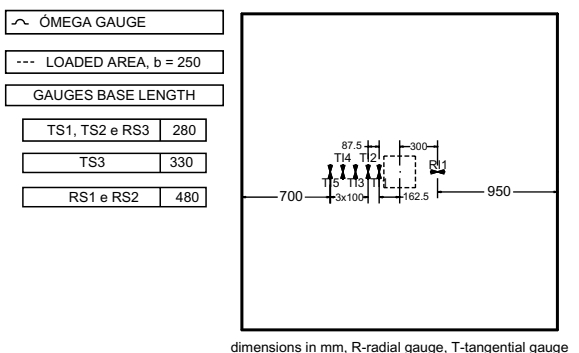

dimensions in $\mathrm{mm}$, $\mathrm{R}$-radial gauge, $\mathrm{T}$-tangential gauge

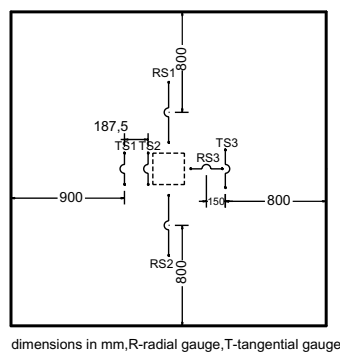

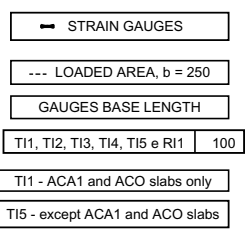

Figure 3. Location of the strain gauges on the top (left hand side) and bottom (right hand side) slabs' concrete surface 
EC

30,6

806
Slab deflections were measured on the top side of the slabs using five $541.2 \mathrm{~mm}$ spaced linear variable differential transformers (LVDT), Figure 4.

\section{Nnumerical simulation of punching tests}

\subsection{Introduction}

The quality of the results obtained by a non-linear analysis is strongly influenced by the experience of the user who must choose appropriate crack model, iterative process, and convergence criterion. In addition, shear and punching shear related problems are complex and extremely sensitive to the iterative method, increment size and the tolerance used for convergence: the solution quickly diverges when very tight tolerances are adopted; however for wide tolerances a poor reliability of the numerical solution should be expected.

Performance of a numerical model can be assessed by comparing FEA results with known experimental tests properly instrumented. The capability of DIANA (2008) software to simulate the punching behaviour of the tested slabs is discussed in this study.

\subsection{Element type and mesh}

The slab models were modelled using 1,600 isoparametric 20 nodded solid elements, being each element divided into four horizontal layers of equal thickness 18/4 (slab thickness equal to $18 \mathrm{~cm}$ ). Quadratic interpolation with reduced $3 \times 3 \times 2$ Gauss integration rule was adopted.

Finite elements' meshing was carried out automatically based on the exact geometry of the slab specimens. In the three lower layers (Figure 5) the crack bandwidth, $h$, is related to the size of the finite element mesh as follows:

$$
h=\sqrt[3]{V_{e l} / n}
$$

where, $\mathrm{V}_{\mathrm{el}}$ - finite element volume; $\mathrm{n}$ - number of Gauss points (GP) of finite element.

Figure 4.

LVDT's location

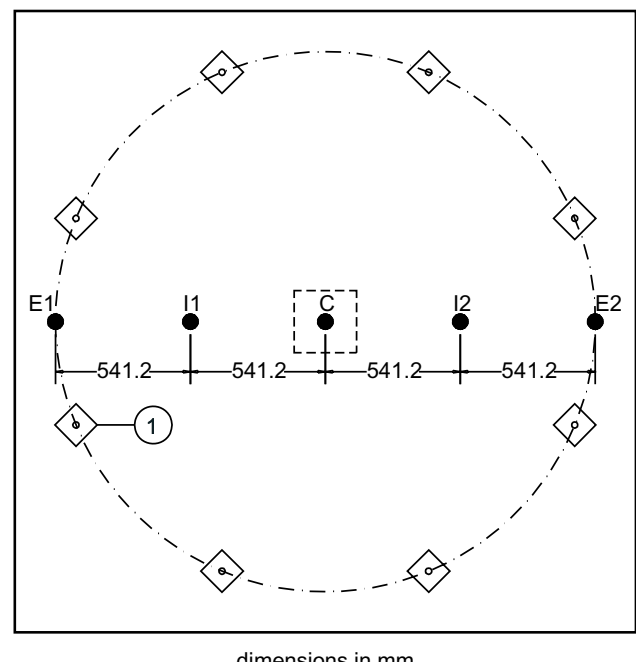

(1) steel plate $120 \times 120 \times 20$

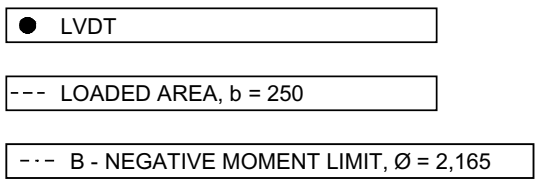




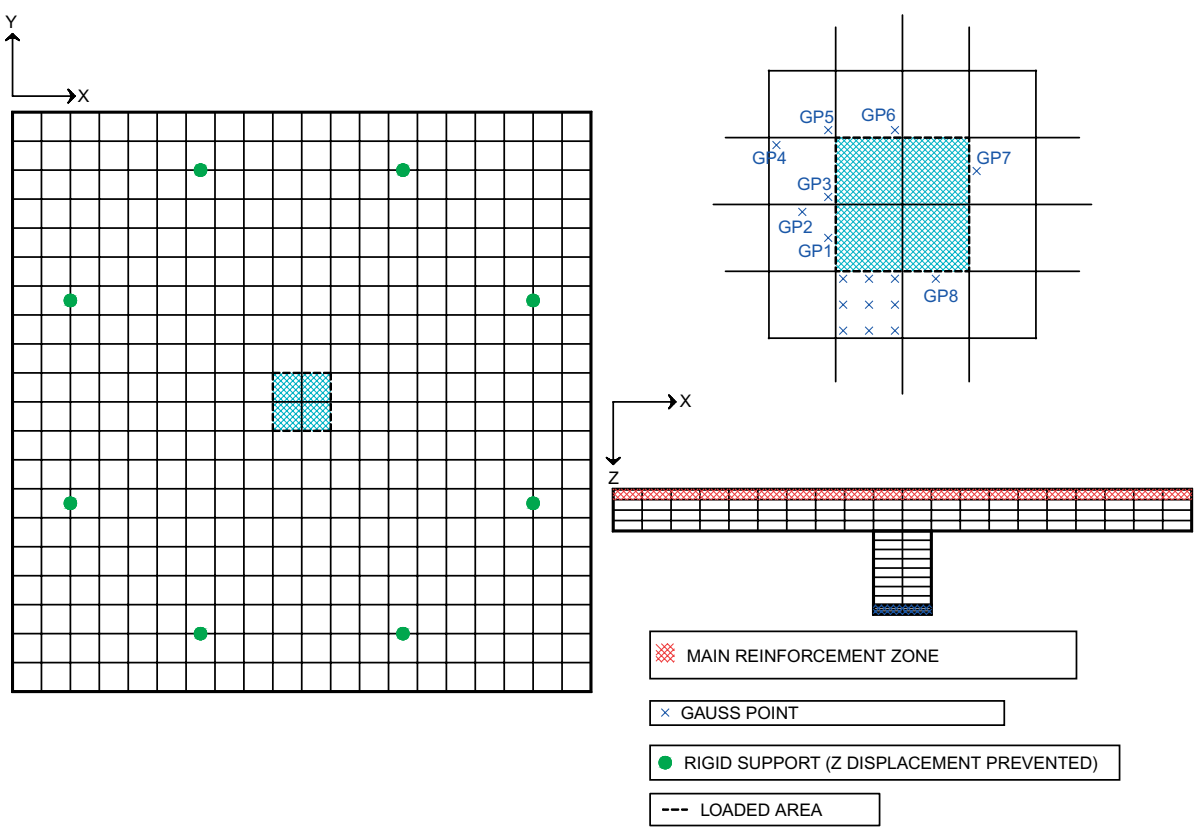

\section{Punching shear analysis}

807

The crack bandwidth is considered to be equal to the edge size of the cube with the same volume as the one associated with each GP of the finite element.

The longitudinal and shear (slabs ACA1 and AEA1) reinforcements were modelled using distributed finite elements embedded in concrete elements and discreetly (bar elements), respectively. The properties of the reinforcement were modelled using the von Mises criteria and $v=0.30$.

\subsection{Formulation}

Non-linear tensile behaviour of cracked concrete was simulated using two available formulations: the smeared crack model based on both the concept of strain decomposition (SD), and the total strain with fixed orthogonal cracks (TSF). Distinct behaviours were observed as it will be shown above. The convergence criteria is formulated in terms of energy with $\xi=1 \times 10^{-4}$ tolerance, allowing the analysis to continue on the occurrence of a non-converged increment. Regarding SD based analysis, the employed iterative method is the Secant method (BFGS); for TSF analysis the algorithm that minimizes the iterative calculation time has shown to be the modified Newton-Raphson method.

Shear reinforcement and concrete strains (top and bottom faces) are compared with those obtained by numerical analysis in the corresponding (nearest) GP.

In the SD concept based analysis the values $\phi_{0}=35^{\circ}, \psi_{0}=12.5^{\circ}$ and $\alpha=60^{\circ}$ were taken for the internal friction angle, dilatancy angle and the limit value of the threshold angle, respectively. The Poisson's ratio of concrete was taken $v=0.20$ together with the linear tension cut-off criteria.

TSF based analysis does not correctly take in account the decrease of elastic strains along with the decrease of orthogonal strains since a constant value is adopted for 
EC

30,6

\section{8}

Table III.

Values of main parameters used in the numerical simulations

Poisson's coefficient, $v$, even for cracked concrete. Consequently, the value $v=0$ was assumed in the analysis. As well as for the experimental program, the numerical loading was applied using displacement control. Comparison between numerical results and tests data is carried out. All the results presented below correspond to converged increments unless otherwise stated.

\subsection{Numerical simulations}

In a first SD numerical analysis, bond between concrete and longitudinal reinforcement was indirectly simulated by applying the tension stiffening concept to the concrete layer comprising main reinforcement (red elements in Figure 5). Linear tension softening is considered in the three remaining layers, along with fracture mode $\mathrm{I}, \mathrm{G}_{\mathrm{F}}$, according to CEB-FIP MC 90 (CEB-FIP, 1993), as shown in Table III. Due to cracking, the concrete shear stiffness is usually reduced. The remaining stiffness is quantified by the shear retention factor, $\beta_{\mathrm{SD}}$. At this point, the usual value $\beta_{\mathrm{SD}}=0.100$ was adopted. The obtained load-deflection curves (SD_C_Stiff) are consistently stiffer than the experimental response. Thus, for a given load, numerical behaviour presents lower deflections than those experimentally observed (Figure 6).

Similar results were obtained for a second analysis carried out using the TSF cracking model (TSF_C_Stiff curves in Figure 6) which may be justified by the slow degradation of available energy on cracks.

Further FEA were then conducted neglecting the contribution of concrete between cracks in top layer, maintaining the above referred softening law in the lower layers,

\begin{tabular}{|c|c|c|c|c|c|c|c|c|}
\hline \multirow[b]{2}{*}{ Slab } & \multirow[b]{2}{*}{$\begin{array}{c}\mathrm{G}_{\mathrm{F}} \\
\left(\mathrm{Nm} / \mathrm{m}^{2}\right)\end{array}$} & \multirow[b]{2}{*}{$\begin{array}{c}P_{u, \exp } \\
(\mathrm{kN})\end{array}$} & \multirow[b]{2}{*}{$\begin{array}{l}\beta_{\mathrm{SD}} \\
(\%)\end{array}$} & \multirow{2}{*}{$\begin{array}{l}\text { SD_C } \\
\mathrm{P}_{\mathrm{u}, \text { num }} / \mathrm{P}_{\mathrm{u}, \exp } \\
(-)\end{array}$} & \multicolumn{2}{|c|}{ SD_V } & \multicolumn{2}{|r|}{ TSF_C } \\
\hline & & & & & $\begin{array}{c}\text { Pruijssers } \xi \\
\qquad(-)\end{array}$ & $\overline{\mathrm{P}}_{\mathrm{u}, \text { num }} / \mathrm{P}_{\mathrm{u}, \exp }$ & $\begin{array}{r}\beta_{\mathrm{TSF}} \\
(\%)\end{array}$ & $\mathrm{P}_{\mathrm{u}, \text { num }} / \mathrm{P}_{\mathrm{u}, \exp }$ \\
\hline $\mathrm{ACO}$ & 100 & 685 & 5.5 & 1.00 & 8.25 & 1.03 & 1.5 & 1.01 \\
\hline AE0 & 112 & 468 & 2.5 & 1.00 & 8.45 & 1.04 & 2.5 & 1.01 \\
\hline ACA1 & 98 & 840 & 4.5 & 0.98 & 7.30 & 1.00 & 4.0 & 0.99 \\
\hline AEA1 & 113 & 626 & 5.5 & 1.01 & 5.60 & 0.99 & - & - \\
\hline $\mathrm{FC} 0$ & 78 & 651 & 6.5 & 1.02 & 6.25 & 1.01 & 3.4 & 1.02 \\
\hline FE0 & 75 & 373 & 6.0 & 1.01 & - & - & 3.5 & 1.02 \\
\hline
\end{tabular}

Figure 6.

Comparison between experimental and numerical load-deflection responses
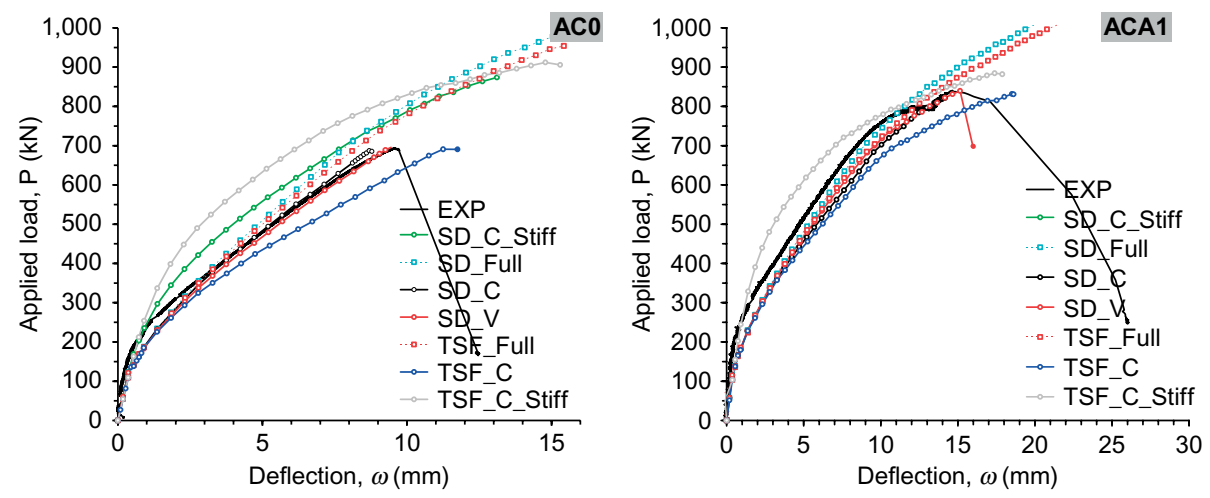
and enforcing a full shear stiffness retention, $\beta_{\mathrm{SD}}=\beta_{\mathrm{TSF}}=1.0$, to the entire slab (SD_Full and TSF_Full curves in Figure 6). The numerical approximation to the experimental response is then significantly enhanced but still it was not possible to identify a numerical evidence of failure.

These results show that the mechanical properties addressed to the layer of elements comprising the main reinforcement are of utmost importance mainly regarding the predicted stiffness of the load-deflection behaviour. Although the deformational response could be approximately reproduced, the numerical analyses were not able to clearly reveal a limit load, nor the abrupt loading capacity decay observed in experimental tests. Therefore, the post-punching behaviour could not be reproduced in the simulation.

As known, an accurate simulation of structures failing in shear is extremely difficult to achieve. In punching failure, the deformation characteristics in the cracked region and the generated shear stresses must be precisely defined. Moreover, the interaction between parameters concerning the crack normal strain $\varepsilon_{\mathrm{nn}}^{\mathrm{cr}}$ (characterized by mode I) and the crack distortion, $\gamma^{\mathrm{cr}}$ (associated to fracture modes II and III) must be accounted for. Such interaction is not always taken into consideration in most computer codes, as it is the case of DIANA. Therefore, the influence of shear retention model should appear of utmost importance. The accuracy of the simulations of punching shear behaviour is strongly influenced by the value of the shear retention factor $(\beta)$, which appears to be the main precision determining parameter.

Several authors sustain that when failure is dominated by fracture mode I, the influence of the value of $\beta$ appears to be irrelevant. However, for failures dealing simultaneously with fracture modes I and II, as it is the case for flat slabs failing in punching, the numerical response is strongly dependent on the function that defines the cracked concrete shear stiffness (Barros, 1995; Frénaij, 1989).

Consequently, further simulations (SD and TSF cracking models) were conducted using different $\beta$ values which were successively adjusted in order to optimize the concordance between numerical and experimental behaviour. The corresponding obtained load-deflection responses are also shown in Figure 6, referenced as SD_C and TSF_C. For those simulations and for a given slab, the different $\beta$ values indicated in Table III can be justified by the following expression:

$$
\beta_{T S F}=\frac{\beta_{S D}}{1-\beta_{S D}}
$$

The values of $\beta$ factor which provided the finest estimation for the different simulations ( $\beta_{\mathrm{SD}}$ and $\beta_{\mathrm{TSF}}$ ) are listed in Table III. It is important to note that this was the only parameter subjected to successive iteration throughout the numerical analysis.

Furthermore, SD cracking model simulations were improved by the inclusion of a user supplied subroutine that allows the variation of $\beta$ shear stiffness retention factor according to the Pruijssers (1988) variable shear stiffness law, by means of the $\xi$ parameter. These simulations (SD_V curves in Figure 6) produced accurate results as well.

In order to verify the close agreement between numerical simulations and experimental failures, the comparison between the stress state of the GP located on the concrete bottom layer (Figure 5) and the associated failure surface was performed. Figure 7 shows the obtained result for the SD_V analysis of ACA1 slab.

\section{Punching shear analysis}

809 
EC

30,6

\section{0}

Figure 7.

Gauss points stress state evolution (ACA1 slab, SD_V analysis)
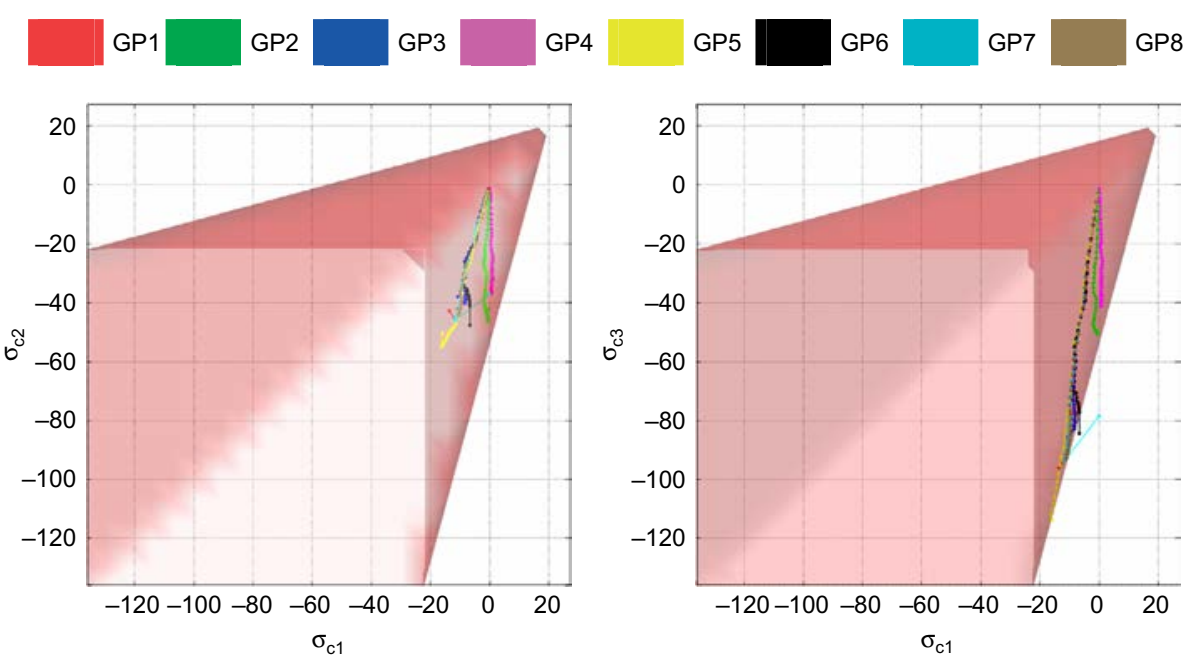

As one can also shown in Figure 6, structural behaviour of the different slabs was correctly reproduced. Convergence between numerical and experimental responses was solely achieved by successive variations of the $\xi$ parameter (Table III).

In Figure 6, the filled dots on the numerical curves close to the peak load indicate a non-converged displacement increment. Actually, for those analyses, it was not possible to reach convergence beyond that increment even when the increments size was significantly reduced. It should be noted that the numerical failure - no converged iterative procedure - may not correspond to the experimental collapse of the structure.

The bottom layer from the eight layers of GP distributed along the slab thickness (Figure 5) is considered for comparison given that major compressive stresses are located near the slab to column connection. As it is shown, for the load increment corresponding to the numerical failure, the stress state of several GP presenting an important softening behaviour overpasses the failure surface.

The identification of numerical shear failures is mainly achieved by the crack pattern as well as by the concrete softening diagram at the slab-column edge. By mean of the variation of the principal stresses orientation at ultimate load, crossing the failure surface (Figure 7), one can verify that the punching failure is accurately captured by the numerical analysis.

\section{Comparison of numerical and experimental results}

4.1 Crack pattern

Crack pattern, slab deformation under ultimate load and incremental deformation for the final loading increment of slab ACA1 are shown in Figure 8. A good accordance between the numerical and experimental behaviours is obtained.

The evident curvature inflexion in incremental slab deformation (Figure 8(d)) can be related with the decrease of the load-carrying capacity of the slab.

\subsection{Concrete tensile strains}

Figure 9 shows the evolution of concrete tensile strains with applied load P both for experimental and numerical results, on tangential $(\mathrm{T})$ and radial (R) directions. 


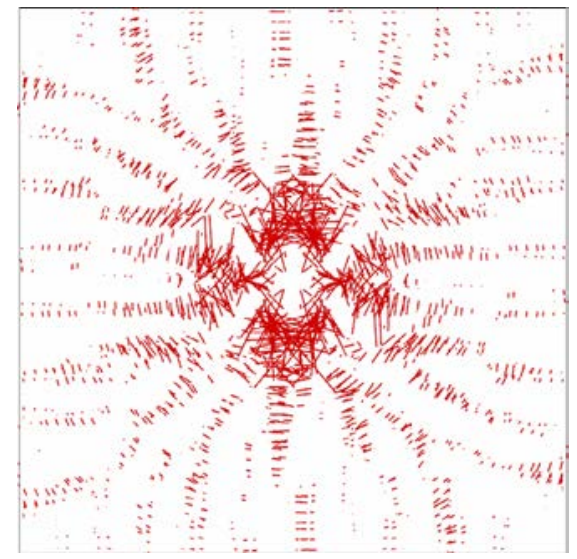

(a) Cracking pattern with normal crack opening vectors $(50 \times)$

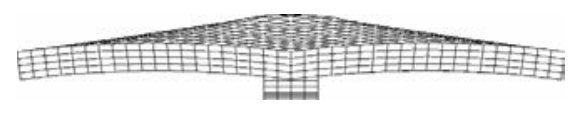

(c) Slab deformed shape $(10 \times)$ at numerical ultimate load

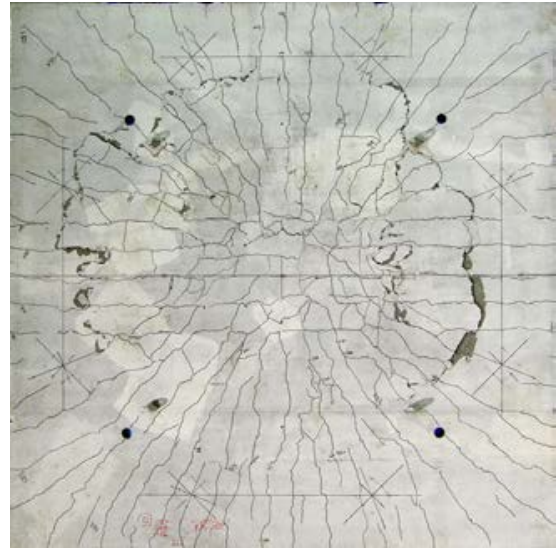

(b) Experimental cracking pattern

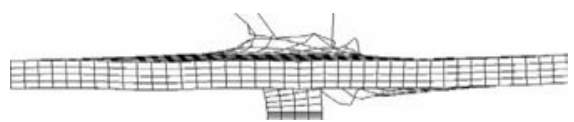

(d) Slab incremental deformed shape $(300 \times)$ at numerical ultimate load

\section{Punching shear analysis}

811

Figure 8. Comparison between numerical and experimental results

(ACA1 slab, SD_V analysis)

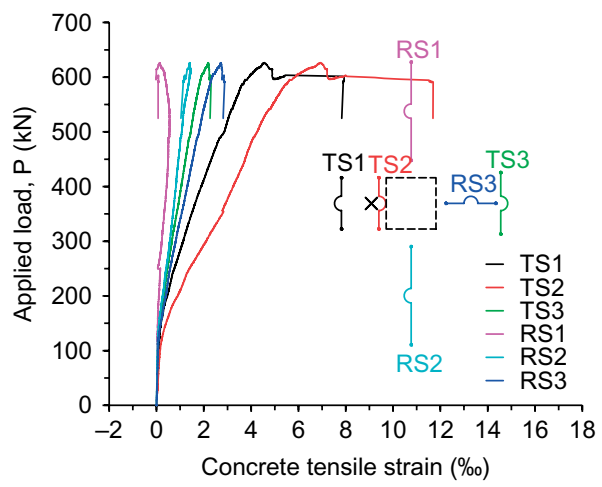

(a) Experimental

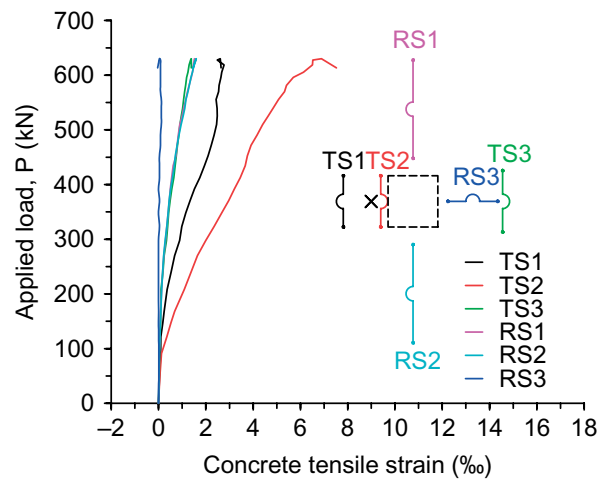

(b) Numerical
Figure 9.

Comparison between experimental and numerical tensile concrete strains (AEA1 slab, SD_C analysis)

\subsection{Concrete compressive strains}

The evolution of concrete compressive strains (bottom face) with applied load $\mathrm{P}$ both for experimental and numerical results can be shown in Figure 10.

\subsection{Shear reinforcement strains}

Shear reinforcement strains evolution with increasing applied load can be shown in Figure 11. 
EC

30,6

812

Figure 10.

Comparison between experimental and numerical compressive concrete strains (AE0 slab, TSF_C analysis)

Figure 11.

Comparison between experimental and numerical shear reinforcement strains (ACA1 slab, SD_V)

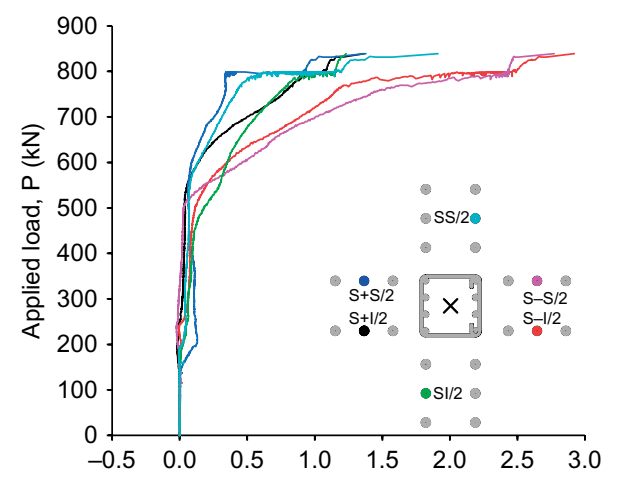

(a) Experimental

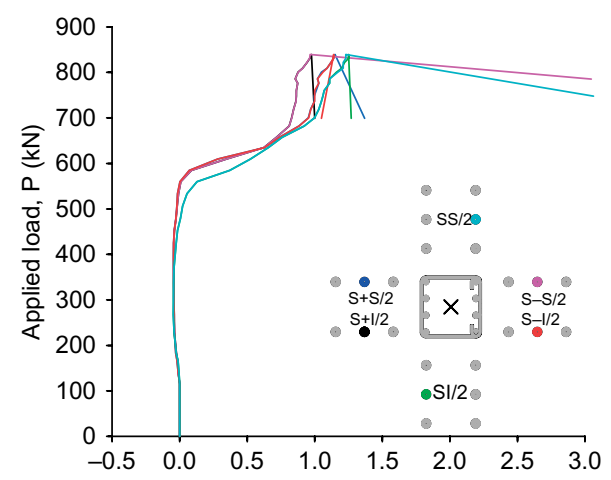

(b) Numerical

The shear studs only presented measurable deformation for loads greater than approximately third-fourth of the ultimate load. The maximum obtained value of shear reinforcement strain is about $2.5 \%$, which is approximately related to a $500 \mathrm{MPa}$ steel stress. This value is however higher than the corresponding design value suggested by several codes (CEB-FIP, 1993; CEN, 2004). Even so, the values of the shear reinforcement strains measured in the punching tests show a good accordance with those obtained by numerical modelling.

\section{Conclusions}

An extensive experimental program on real scale flat slab models under shear punching was carried out in order to assess the influence of load eccentricity and the contribution of shear reinforcement to the punching resistance and failure mechanism.

The behaviour of tested slabs was simulated by a non-linear finite element analysis performed with DIANA software. The smeared crack model based on both the concept of strain decomposition (SD) and total strain with fixed orthogonal cracks approach (TSF) was used for the analysis. 
The comparison between experimental and numerical results leads to the following conclusions:

- Indirect simulation of bond between concrete and reinforcement by using the tension stiffening concept revealed an excessively rigid structural behaviour. This could be due to the dissipation mechanism of available energy along cracks. Results demonstrate that concrete tensile properties assigned to the finite element layer containing the main reinforcement govern the stiffness of the load-deflection behaviour.

- Good agreement was found between the predicted and the observed deformational behaviours. Nevertheless, the reproduction of the punching ultimate capacity is strongly dependent from the adopted value for the shear retention factor $(\beta)$, which appears to be the major decisive parameter. The capture of experimental failures was obtained by successive adjustments of this parameter.

- Among the different numerical analysis, the best agreement was obtained within the simulations in which the value of $\beta$ varies according to variable shear stiffness law derived by Pruijssers.

- The values of the concrete and shear reinforcement strains obtained by the numerical modelling show a good accordance with the ones measured in the punching tests. The experimental crack pattern could also be correctly reproduced.

\section{References}

Barros, J.A.O.d. (1995), Comportamento do Betão Reforçado com Fïbras - Análise Experimental e Modelação Numérica, Faculdade de Engenharia da Universidade do Porto, Porto (in Portuguese).

CEB-FIP (1993), Model Code 1990, Comité Euro-International du Béton, Thomas Telford Services Ltd, Lausanne, p. 437.

CEN (2004), EN 1992-1-1: Eurocode 2: Design of Concrete Structures - Part 1-1: General Rules and Rules for Buildings, Central Secretariat, Brussels.

DIANA (2008), Finite Element Analysis - Release 9.3, D.o.C. Research, Editor, TNO Diana BV, Delft.

Frénaij, J.W.I.J. (1989), Time-Dependent Shear Transfer in Cracked Reinforced Concrete, Delft University of Technology, Delft, p. 183.

IPQ (2003a), Norma Portuguesa Definitiva NP EN 12390-3: Ensaios do betão endurecido - Parte 3: Resistência à compressão dos provetes de ensaio, IPQ, Davie, FL (in Portuguese).

IPQ (2003b), Norma Portuguesa Definitiva NP EN 12390-6: Ensaios do betão endurecido - Parte 6: Resistência à tracção por compressão de provetes, IPQ, Davie, FL (in Portuguese).

IPQ (2003c), Norma Portuguesa Definitiva NP EN 12390-7: Ensaios do betão endurecido - Parte 7: Massa volumica do betão endurecido, IPQ, Davie, FL (in Portuguese).

ITeC (2006), Documento de adecuación al uso, Institut de Tecnologia de la Construcció de Catalunya, Barcelona, p. 40 (in Spanish).

LNEC (1993), E 397-1993 - Especificação LNEC - BETÕES - determinação do módulo de elasticidade em compressão, LNEC, Lisboa (in Portuguese).

LNEC (1998), E 450-1998 - Especificação LNEC - Varões de aço A500 NR para armaduras de betão armado - características, ensaios e marcação, LNEC, Lisboa (in Portuguese).

\section{Punching shear analysis}

813 
EC

30,6

814
LNEC (2002), E 460-2002 - Especificação LNEC - Varões de aço A500 NR de ductilidade especial para armaduras de betão armado - características, ensaios e marcação, LNEC, Lisboa (in Portuguese).

Moreno, C. (2010), Lajes Fungiformes. Contribuições para a Compreensão do seu Comportamento, Departamento de Engenharia Civil., Faculdade de Engenharia da Universidade do Porto, Porto, p. 220 (in Portuguese).

Moreno, C. and Sarmento, A.M. (2008), "Bridge science and applications with engineering towards innovative solutions for construction”, Punching Shear in Eccentrically Loaded Flat Slabs, CCC2008 International Conference-Challenges for Civil Construction 2008, A. Torres Marques, Porto, p. 12 (Abstract: 140-141).

Pruijssers, A.F. (1988), Aggregate Interlock and Dowel Action Under Monotonic and Cyclic Loading, Delft University of Technology, Delft, p. 165.

\section{Corresponding author}

Carlos L. Moreno can be contacted at: c-moreno@ipb.pt 